\title{
A Large Calcifying Cystic Odontogenic Tumor Occupying the Maxillary Sinus: A Case Report and Review of Literature
}

\author{
Hiroshi Nakamura1,2, Shigehiro Tamaki ${ }^{1,2}$, Nobuhiro Ueda1, Nobuhiro Yamakawa1, \\ Yuichiro Imai ${ }^{3}$, Tadaaki Kirita ${ }^{1}$ \\ ${ }^{1}$ Department of Oral and Maxillofacial Surgery, Nara Medical University, Nara, Japan \\ ${ }^{2}$ Department of Oral Surgery, Takai Hospital, Tenri, Japan \\ ${ }^{3}$ Department of Oral Surgery, Rakuwakai Otowa Hospital, Kyoto, Japan \\ Email:nakahiro@naramed-u.ac.jp
}

How to cite this paper: Nakamura, H., Tamaki, S., Ueda, N., Yamakawa, N., Imai, Y. and Kirita, T. (2017) A Large Calcifying Cystic Odontogenic Tumor Occupying the Maxillary Sinus: A Case Report and Review of Literature. Open Journal of Stomatology, 7, 291-298.

https://doi.org/10.4236/ojst.2017.75023

Received: April 12, 2017

Accepted: May 24, 2017

Published: May 27, 2017

Copyright $\odot 2017$ by authors and Scientific Research Publishing Inc. This work is licensed under the Creative Commons Attribution International License (CC BY 4.0).

http://creativecommons.org/licenses/by/4.0/

\begin{abstract}
Calcifying cystic odontogenic tumor (CCOT) is an uncommon benign cystic neoplasm of the jaw that develops from the odontogenic epithelium. It is clinically characterized as a painless-slow-growing tumor that affects the maxilla as well as the mandible, and generally occurs in young adults in the third or fourth decade of life. Herein, we present the case of a 16-year-old Japanese boy who showed a CCOT in the maxillary sinus. Panoramic radiography showed a unilocular lesion in the left maxillary sinus. Computed tomography showed an approximately 5 -cm well-defined unilocular expansile lesion with multiple radiopaque calcific specks, arising from the left maxillary alveolar ridge. The lesion was surgically removed, under general anesthesia, and the patient was followed up for 3 years after the surgery, and there have not been any signs of recurrence.
\end{abstract}

\section{Keywords}

Calcifying Cystic Odontogenic Tumor, Maxillary Sinus, Ghost Cells

\section{Introduction}

The calcifying odontogenic cyst (COC) was first described as a distinct entity by Gorlin et al. [1] in 1962. In 2005, it was classified as a tumor and termed a calcifying cystic odontogenic tumor (CCOT) by the World Health Organization because of its neoplastic behavior [2]. CCOT is normally a painless slow growing tumor and may occur in association with other odontogenic tumors, such as odontomas [3]. 
Histopathologically, CCOT is usually composed of a cystic cavity with a fibrous capsule lined by odontogenic epithelium. Masses of ghost cells may occur in the epithelial lining and these often become may be calcified [2].

Radiographically, CCOT generally appears as a unilocular or multilocular radiolucent area with well-defined margins and may contain radiopaque materials [4], in varying quantities and shapes.

This report describes a case of CCOT occupying the maxillary sinus of a 16-year-old Japanese boy.

\section{Case Report}

A 16-year-old boy, with no relevant medical history, presented with swelling in the left maxillary region with nasal obstruction and was referred to the Department of Oral and Maxillofacial Surgery at Nara Medical Hospital. Physical examination revealed mild facial asymmetry due to the swelling on the left cheek. Oral examination revealed a firm swelling in the alveolar mucosa and gingiva-buccal fold in the left upper posterior region (Figure 1). The overlying mucosa was normal and the lesion was elastic hard to palpation. Panoramic radiograph showed a unilocular lesion in the left maxillary sinus and root resorption in the left maxillary molars (Figure 2). Electric Pulp Test with 24, 25, 26, showed negative result. Computed tomography (CT) showed an approximately $5-\mathrm{cm}$ well-defined unilocular expansile lesion with multiple radiopaque calcific specks, arising from the left maxillary alveolar. It extended into the left maxillary sinus and left nasal cavity and elevated the left orbital floor (Figure 3).

Aspiration of the lesion showed a citrine yellow serous liquid content. Incisional biopsy revealed a benign cystic lesion with typical histologic features of CCOT.

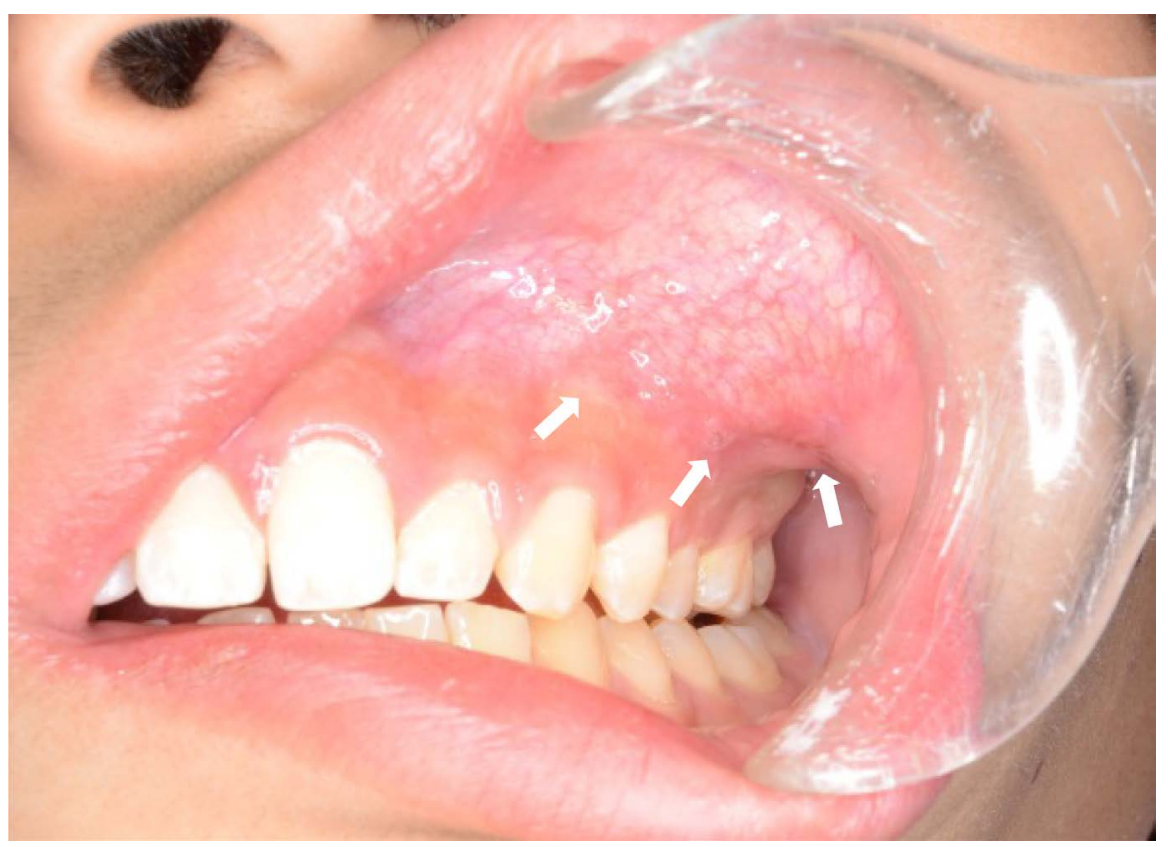

Figure 1. Intraoral examination showed a firm swelling in the alveolar mucosa and gingiva-buccal fold in the left upper posterior region (arrow). 


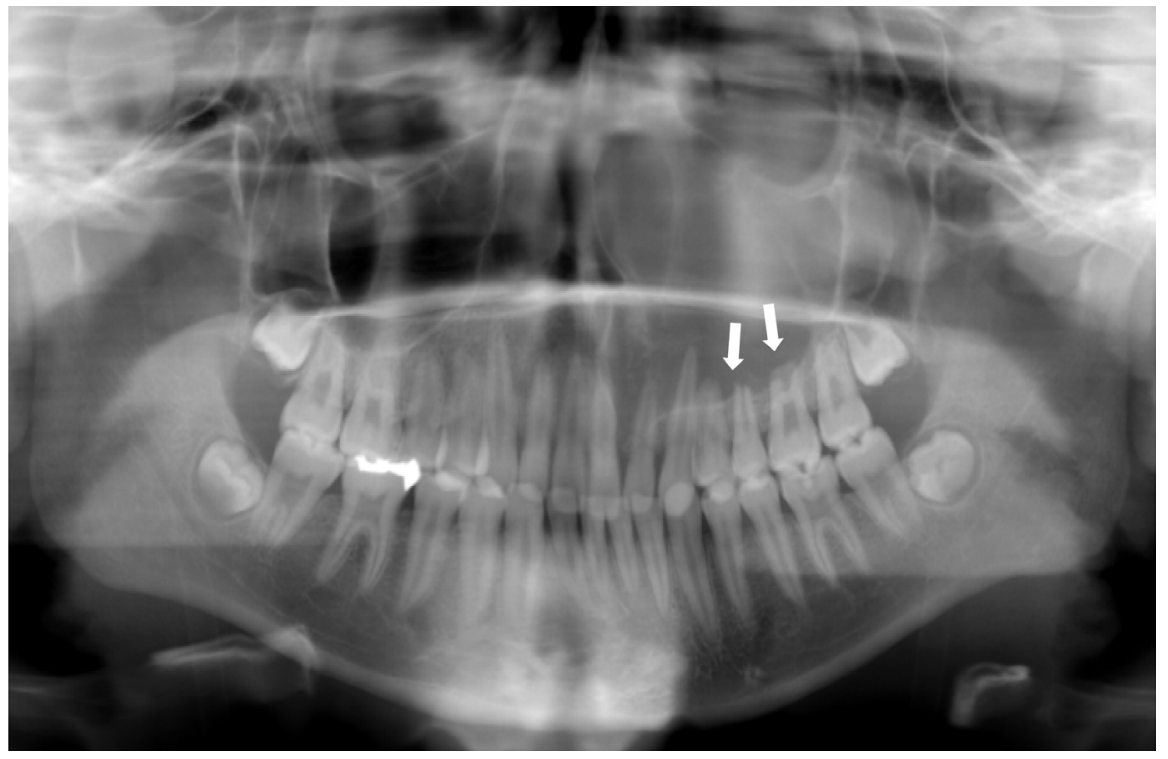

Figure 2. Panoramic radiograph showed a unilocular lesion in the left maxillary sinus and root resorption in the left maxillary molars (arrow).

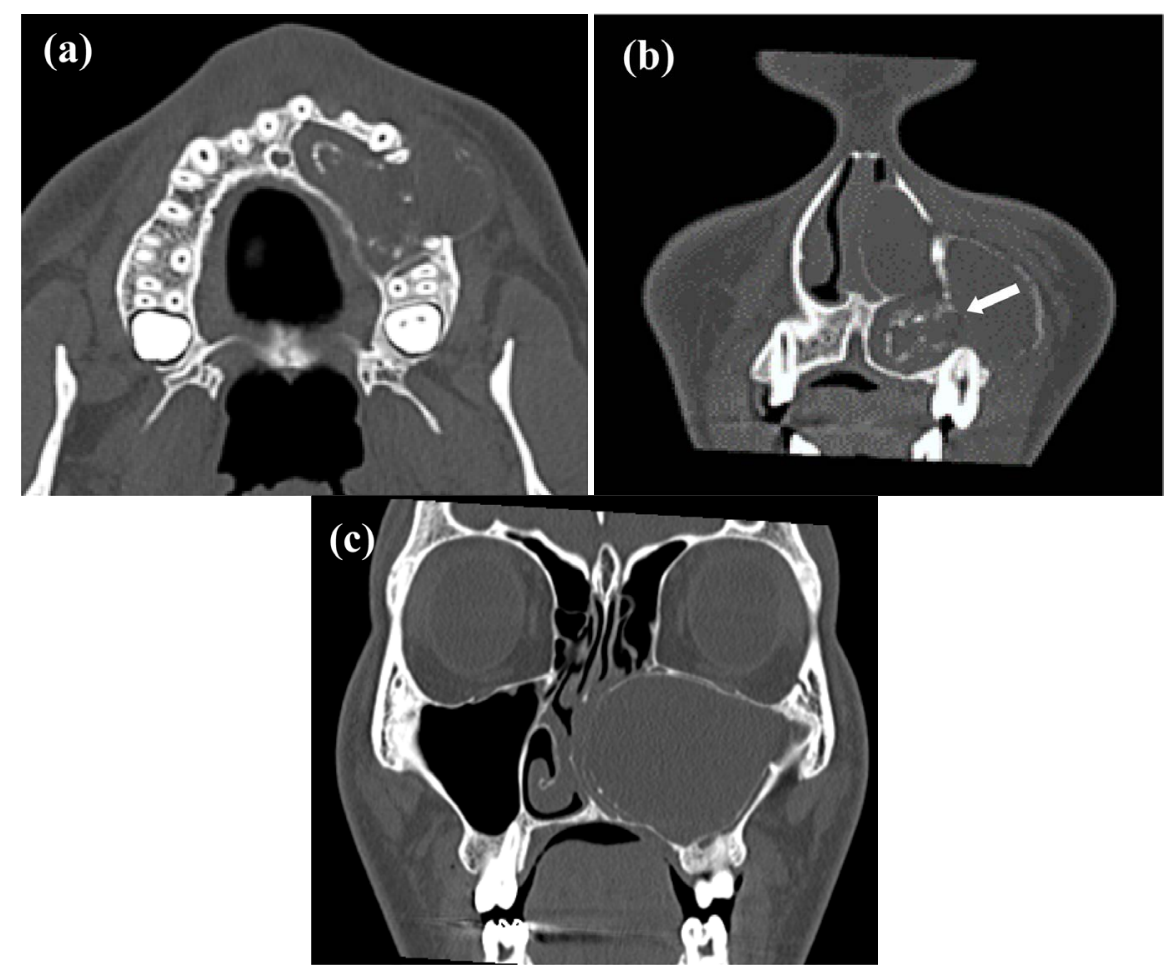

Figure 3. (a) Axial image; (b) Coronal image, anterior teeth area. (c) Coronal image, posterior teeth area. CT showed a well-defined unilocular expansile lesion with multiple radiopaque calcific specks (arrow) arising from the left maxillary alveolar ridge.

Root canal therapy followed by surgical enucleation of the cystic lesion and apicoectomy with 24, 25, 26 was carried out under general anesthesia. An intraoral approach was used, and the lesion was exposed and could be easily removed from the bone without adhesion (Figure 4). The excised tumor measured $40 \times$ $45 \mathrm{~mm}$, had a smooth surface, and was elastic soft to palpation. Sectional view 
showed a unicystic lesion containing calcifications in the cystic wall (Figure 5).

Microscopically, the cystic wall was lined by stratified squamous epithelium with a columnar and cuboidal basal layer. Numerous ghost cells and calcified particles were present within the lining epithelium (Figure 6). A histopathological diagnosis of CCOT was made. Postoperative healing was uneventful, and no recurrence of the lesion was reported in the 3-year follow-up period.
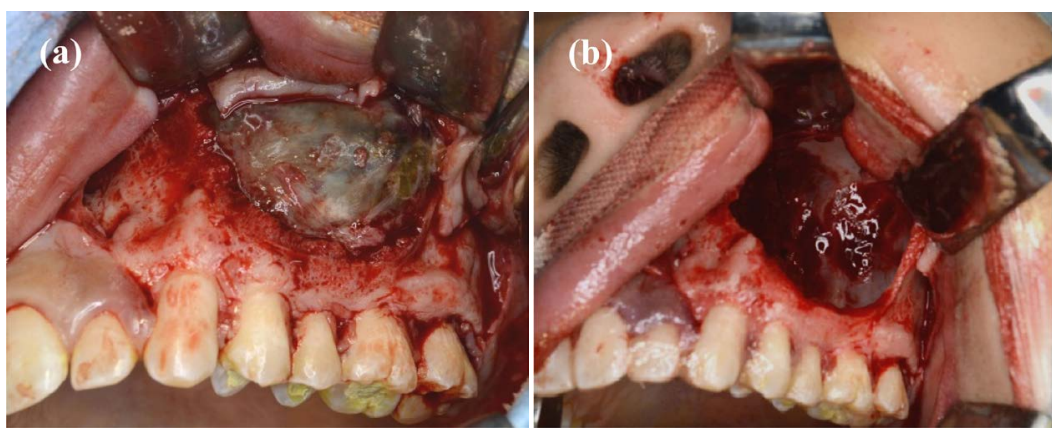

Figure 4. The lesional area after raising the mucoperiosteal flap (a) and the lesion being surgically removed (b).

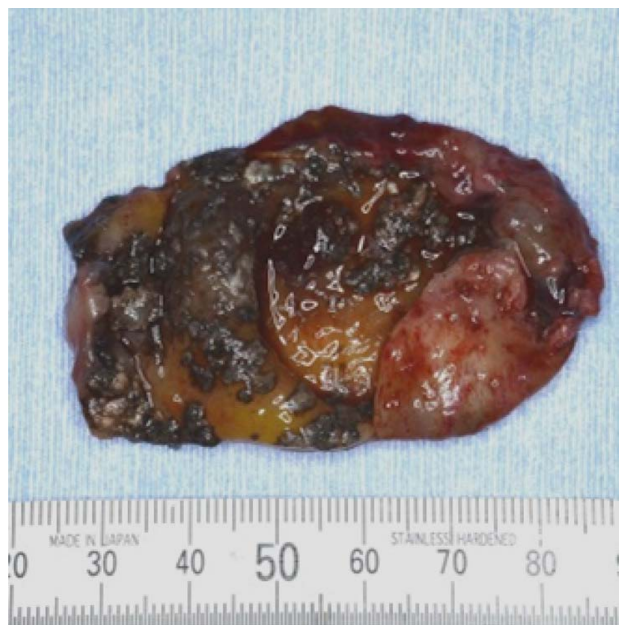

Figure 5. Sectional view showed a unicystic lesion containing calcifications.

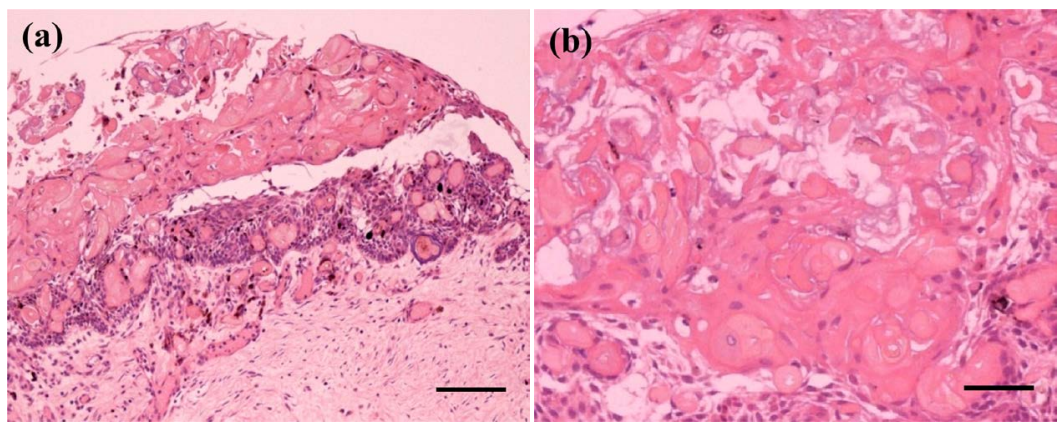

Figure 6. (a) The cystic wall was lined by stratified squamous epithelium with clusters of ghost cells in the superficial layer. (b) Numerous ghost cells and calcified particles were present within the epithelial lining (hematoxyline-eosin stain; (a) original magnification $\times 40$; scale bar $=250 \mu \mathrm{m}$; (b) original magnification $\times 100$, scale bar $=100 \mu \mathrm{m})$. 


\section{Discussion}

CCOT is a relatively rare lesion that represents only about $2 \%$ of all odontogenic pathological changes in the jaw [5] [6]. It is clinically characterized as a painless-slow-growing tumor, that affects the maxilla as well as the mandible, and generally occurs in young adults in the third or fourth decade of life. It exhibits no sexual predilection and is most commonly seen in the anterior region [7] [8]. CCOT can present alone, as in the present case, or is associated with other odontogenic tumors, such as odontomas, adenomatoid odontogenic tumors, and ameloblastomas [9].

Microscopically, CCOT usually presents as a cystic cavity with a fibrous capsule lined by odontogenic epithelium with columnar or cuboidal basal cells resembling ameloblasts. The typical histological feature is the presence of varying number of aberrant epithelial cells, without nuclei, called "ghost cells".

Differential diagnosis of CCOT includes adenomatoid odontogenic tumor, ameloblastic fibro-odontoma, and calcifying epithelial odontogenic tumor. Definitive diagnosis can be made histologically [4].

Odontogenic tumors of the jaw-bones show a wide range of radiographic manifestations that result from the presence of dental components of ectodermal and mesodermal originthe jaw-bones [10]. Specifically, as CCOT is a mixed lesion, it has a wide range of radiologic appearances. Radiographically, CCOT generally appears as a well-defined, unilocular, or multilocular lesion with occasional radiopaque deposits of varying sizes and opacities. Root resorption and root divergence are common-and an associated unerupted tooth is observed in about $33 \%$ of the cases [11].

CT is important for investigating the internal structures of the lesion and has been considered very useful for clinical diagnosis and treatment planning [12]. In the present case, CT showed internal calcification in the lesion, which is an important characteristic that was not detected by panoramic radiography.

To review previous case reports of the CCOT expanding to the maxillary sinus published from 2001-2016, a search was carried out in the internet site PUBMED. A review of 8 cases, including the present case, is presented in Table 1. In the 8 cases, the patient age ranged from 5 to 45 years, with a mean age of

Table 1. Previous reports of the CCOT expanding to the maxillary sinus.

\begin{tabular}{|c|c|c|c|c|c|c|}
\hline Author & Age/sex & Size $(\mathrm{mm})$ & Root resorption & Impacted tooth & Associated tumor & Follow up/recurrence \\
\hline Jinbu et al. [15] & $15 / F$ & $30 \times 20$ & $(-)$ & $(+)$ & odontoma & NA/NA \\
\hline Daniels et al. [13] & $45 / \mathrm{M}$ & NA & $(+)$ & $(+)$ & None & 4 years/No recurrence \\
\hline Reyes et al. [16] & $5 / \mathrm{M}$ & 35 & NA & NA & None & 1 year/No recurrence \\
\hline Devilliers et al. [17] & $17 / \mathrm{M}$ & 60 & $(+)$ & $(+)$ & None & NA/NA \\
\hline Gamoh et al. [19] & $4 / \mathrm{M}$ & 25 & $(-)$ & $(-)$ & None & 18 months/No recurrence \\
\hline Phulambrikar et al. [20] & $28 / \mathrm{M}$ & $44 \times 37$ & $(+)$ & $(-)$ & odontoma & NA/NA \\
\hline Present study & $16 / \mathrm{M}$ & $40 \times 37$ & $(+)$ & $(-)$ & None & 3 years/No recurrence \\
\hline
\end{tabular}

$(+)$, positive results; $(-)$, negative results; NA, not available. 
20.8 years. The male:female ratio was 1:3. Root resorption and impacted tooth was observed in 4 out of 8 reported cases.

The discussion about the neoplastic behavior of CCOT is still recent. Yoshida et al. [7] analyzed immunohistochemical features of 16 cases of COC with various histological features, including proliferative type lining epithelium, ameloblastomatous appearance, and combined odontoma, to characterize the cytodifferentiation and cellular activity. They reported that the bcl-2 protein was expressed in the cytoplasm of the lined epithelial cells in 12 cases with COCs, however, the lining epithelial cells sporadically tested positive for the Ki-67 antigen in the nuclei. Immunohistochemical examinations revealed little or no differences in cytodifferentiation and cellular activity among COCs. The results suggested that $\mathrm{COC}$ with various histological features had neoplastic potential and might not be separate entities within the same histological spectrum.

The recommended treatment for CCOT is usually conservative and consists of enucleation with curettage, i.e., enucleation followed by removal of a $1-2 \mathrm{~mm}$ layer of bone around the complete periphery of the cystic cavity with a sharp curette or a bone bur [13]. The purpose of this procedure is to remove epithelial debris that could turn into a recurrent lesion. Occasional recurrences have been reported [13] [14], most of which have occurred over 5 years following initial treatment, usually in elderly patients. We emphasize that the choice of treatment should be individualized for each lesion since radiological and histological features may differ from one lesion to another.

CCOT is a benign odontogenic neoplasm that may exhibit occasional aggressive and recurrent behavior. In the present case, the patient underwent conservative treatment with complete enucleation of the lesion. No recurrence was observed during the follow-up period.

\section{Conclusion}

In conclusion, this was a case of CCOT occupying the maxillary sinus. CT served an important tool in making an appropriate surgical planning of the lesion in the present case. A satisfactory esthetic outcome with no sequelae was achieved.

\section{Consent}

Written informed consent was obtained from the patient for publication of this case report and any accompanying images.

\section{References}

[1] Gorlin, R.J., Pindborg, J.J., Clausen, F.P. and Vickers, R.A. (1962) The Calcifying Odontgenic Cyst: A Possible Analogue of the Cutaneous Calcifying Epithelioma of Malherbe. An Analysis of Fifteen Cases. Oral Surgery, Oral Medicine, Oral Pathology, 15, 1235-1243.

[2] Barnes, L., Eveson, J., Reichart, P. and Sidransky, D., Eds. (2005) World Health Organization Classification of Tumors. Pathology and Genetics of Tumors of the Head and Neck. IARC, Lyon, 313.

[3] Hirshberg, A., Kaplan, I. and Buchner, A. (1994) Calcifying Odontogenic Cyst As- 
sociated with Odontoma: A Possible Separate Entity (Odontocalcifying Odontogenic Cyst). Journal of Oral and Maxillofacial Surgery, 52, 555-558.

https://doi.org/10.1016/0278-2391(94)90087-6

[4] Chindasombatjaroen, J., Kakimoto, N., Akiyama, H., Kubo, K., Murakami, S., Furukawa, S., et al. (2007) Computerized Tomography Observation of a Calcifying Cystic Odontogenic Tumor with an Odontoma: Case Report. Oral Surgery, Oral Medicine, Oral Pathology, Oral Radiology, and Endodontology, 104, e52-e57. https://doi.org/10.1016/j.tripleo.2007.06.025

[5] Verbin, R. and Barnes, L. (2001) Cysts and Cyst-Like Lesions of the Oral Cavity, Jaws, and Neck. In: Barnes, L., Ed., Surgical Pathology of the Head and Neck, 2nd Edition, Marcel Decker, New York, 1437-1555.

[6] Kamboj, M. and Juneja, M. (Sci2007) Ameloblastomatous Gorlin's Cyst. Journal of Oral Science, 49, 319-323. https://doi.org/10.2334/josnusd.49.319

[7] Yoshida, M., Kumamoto, H., Ooya, K. and Mayanagi, H. (2001) Histopathological and Immunohistochemical Analysis of Calcifying Odontogenic Cysts. Journal of Oral Pathology \& Medicine, 30, 582-588. https://doi.org/10.1034/j.1600-0714.2001.301002.x

[8] Li, T.J. and Yu, S.F. (2003) Clinicopathologic Spectrum of the So-Called Calcifying Odontogenic Cysts: A Study of 21 Intraosseous Cases with Reconsideration of the Terminology and Classification. American Journal of Surgical Pathology, 27, 372384. https://doi.org/10.1097/00000478-200303000-00011

[9] Zornosa, X. and Muller, S. (2010) Calcifying Cystic Odontogenic Tumor. Head and Neck Pathology, 4, 292-294. https://doi.org/10.1007/s12105-010-0197-z

[10] Marques, Y.M., Botelho, T.D., Xavier, F.C., Rangel, A.L., Rege, I.C. and Mantesso, A. (2010) Importance of Cone Beam Computed Tomography for Diagnosis of Calcifying Cystic Odontogenic Tumor Associated to Odontoma. Report of Case. Medicina Oral Patologia Oral y Cirugia Bucal, 15, e490-e493.

https://doi.org/10.4317/medoral.15.e490

[11] Uchiyama, Y., Akiyama, H., Murakami, S., Koseki, T., Kishino, M., Fukuda, Y., et al. (2012) Calcifying Cystic Odontogenic Tumor: CT Imaging. The British Journal of Radiology, 85, 548-554. https://doi.org/10.1259/bjr/19841479

[12] Cavalcanti, M.G. and Vannier, M.W. (2000) Measurement of the Volume of Oral Tumors by Three-Dimensional Spiral Computed Tomography. Dentomaxillofacial Radiology, 29, 35-40. https://doi.org/10.1038/sj.dmfr.4600498

[13] Daniels, J.S. (2004) Recurrent Calcifying Odontogenic Cyst Involving the Maxillary Sinus. Oral Surgery, Oral Medicine, Oral Pathology, Oral Radiology, and Endodontology, 98, 660-664. https://doi.org/10.1016/j.tripleo.2004.04.015

[14] Wright, B.A., Bhardwarj, A.K. and Murphy, D. (1984) Recurrent Calcifying Odontogenic Cyst. Oral Surgery, Oral Medicine, Oral Pathology, 58, 579-583.

[15] Jinbu, Y., Tsukinoki, K., Tanobe, K., Yamaguchi, K., Itoh, H., Watanabe, Y., et al. (2001) Calcifying Odontogenic Cyst Associated with Complex and Compound Odontoma: Report of a Case and Immunochemical Study. Oral Medicine \& Pathology, 6, 51-55. https://doi.org/10.3353/omp.6.51

[16] Reyes, D., Villanueva, J., Espinosa, S. and Cornejo, M. (2007) Odontogenic Calcificant Cystic Tumor: A Report of Two Clinical Cases. Medicina Oral, Patologia Oral y Cirugia Bucal, 12, 126-129.

[17] Devilliers, P., Talacko, A.A., Aldred, M.J. and Cure, J.K. (2010) Clinico-Pathologic Conference: Case 3. Calcifying Cystic Odontogenic Tumor (CCOT). Head and Neck Pathology, 4, 339-342. https://doi.org/10.1007/s12105-010-0225-z 
[18] Utumi, E.R., Pedron, I.G., da Silva, L.P., Machado, G.G. and Rocha, A.C. (2012) Different Manifestation of the Calcifying Cystic Odontogenic Tumor. Einstein (São Paulo), 10, 366-370. https://doi.org/10.1590/S1679-45082012000300019

[19] Gamoh, S., Nakashima, Y., Akiyama, H., Shimizutani, K., Sanuki, T., Kotani, J., et al. (2013) A Unique Case of a Calcifying Cystic Odontogenic Tumor. Open Journal of Stomatology, 3, 314-317. https://doi.org/10.4236/ojst.2013.36052

[20] Phulambrikar, T., Vilas Kant, S., Kode, M. and Magar, S. (2015) Cone Beam Computed Tomography Finding in Calcifying Cystic Odontogenic Tumor Associated with Odontoma: A Case Report. Dent Shiraz Univ Med Sci, 16, 374-379.

Submit or recommend next manuscript to SCIRP and we will provide best service for you:

Accepting pre-submission inquiries through Email, Facebook, LinkedIn, Twitter, etc. A wide selection of journals (inclusive of 9 subjects, more than 200 journals) Providing 24-hour high-quality service User-friendly online submission system Fair and swift peer-review system Efficient typesetting and proofreading procedure Display of the result of downloads and visits, as well as the number of cited articles Maximum dissemination of your research work

Submit your manuscript at: http://papersubmission.scirp.org/ Or contact ojst@scirp.org 